\title{
Saltwater Intrusion Modeling in the Aquifer Bounded by Manila Bay and Parañaque River, Philippines
}

\author{
Maria Sharlene L. Insigne, Gyeong-Seok Kim ${ }^{\dagger}$ \\ Department of Construction and Environmental Engineering, Kongju National University, Chungnamdo 331-717, Korea
}

\begin{abstract}
The continual extraction and indiscriminante use of groundwater for residential sectors could cause a decrease in the groundwater level in Parañaque and Las Piñas City; and allows saltwater to penetrate into the aquifer due to the proximity of Manila Bay. This study models the present condition and extent of saltwater intrusion in the aquifer bounded by Parañaque River and Manila Bay. The model is simulated using a 3D finite element modeling software (FEMWATER) that is capable of modeling the groundwater flow condition in the aquifer. Moreover, the model can also be used to predict the future condition of the aquifer for better groundwater management. This study aims to raise public awareness of the extent of the problem and the possible side effects incurred. The model will serve as a basis for further studies on remediation techniques and saltwater intrusion control in the coastal aquifer of Parañaque City.
\end{abstract}

Keywords: FEMWATER, Groundwater modeling, Manila bay, Parañaque river, Philippines, Saltwater intrusion

\section{Introduction}

Water is a primary necessity for life, but remains a problem in urban and coastal areas in the Philippines. The country is rich in natural resources, including water, which are essential for the country's economic development. Water resources of the Philippines include inland freshwater (rivers, lakes, and groundwater), and marine (bay, coastal, and oceanic waters). There is sufficient water; but not enough in highly populated areas, especially during the dry season.

One major source of freshwater is the groundwater. The Philippine's reservoirs cover 50,000 $\mathrm{km}^{2}$. They have a storage capacity of 251,100 MCM. The potential supply from surface water sources is estimated at $126,000 \mathrm{MCM} / \mathrm{yr}$, while that of groundwater is approximately $20,200 \mathrm{MCM} / \mathrm{yr}$ or about $14 \%$ of total water resources potential. Despite these figures, the Philippines ranks among the lowest in terms of freshwater availability per capita at $1,907 \mathrm{~m}^{3}$, compared with the average of $7,045 \mathrm{~m}^{3}$ worldwide and 3,668 $\mathrm{m}^{3}$ in Asia.

According to the National Water Resources Board (NWRB), the consumption of groundwater was distributed as follows: $49 \%$ for domestic sector; $32 \%$ for agriculture; $15 \%$ for industry; and the remaining $4 \%$ for all other sectors.

Surface water is largely used for agriculture (85\%), while industry and domestic sectors sharing the rest. Based on a study conducted by the Japan International Cooperation Agency (JICA), water demand in the Philippines was 29,944 MCM/yr in 1996. It is expected to dramatically increase to up to 86,500
$\mathrm{MCM} / \mathrm{yr}$ in 2025. In fact, water shortages are occuring increasingly nowadays. Due to the constant population growth, the groundwater is used extensively to supplement available surface water to meet the increasing water demand [1].

When fresh water is withdrawn at a faster rate than it can be replenished, a drawdown of the water table occurs with a resulting decrease in the overall hydrostatic pressure. When this happens near an ocean coastal area, salt water from the ocean intrudes into the fresh water aquifer. The result is that fresh water supplies become contaminated with saltwater [2-5]. The coastal areas of Parañaque and Las Piñas City have been experiencing rapid urbanization, leading to extremely high demands for domestic and industrial water sources. According to the National Water Resources Board (NWRB), this has induced saltwater contamination in the aquifer of Parañaque and Las Piñas City [6].

As populations continue to expand in coastal communities, the need for greater groundwater withdrawals is certain to increase. The exploitation and restoration of fresh groundwater in coastal aquifer systems should form part of integrated water management system, comprising surface water and groundwater, in terms of water quantity water quality, and water demand [7]. This study aims to simulate the present condition and extent of saltwater intrusion, as well as the projected extent and degree of salinity concentration in the aquifer bounded by Parañaque River and Manila Bay. The condition of the aquifer will be modeled in terms of salinity. From the model results, the present and future condition of the aquifer will be analyzed and possible remediation procedures will be recommended.

Received February 03, 2010 Accepted March 30, 2010

${ }^{\dagger}$ Corresponding Author

E-mail: gskim23@kongju.ac.kr

Tel: +82-41-566-6003 Fax: +82-41-568-0287 cc This is an Open Access article distributed under the terms of the Creative Commons Attribution Non-Commercial License (http://creativecommons. org/licenses/by-nc/3.0/) which permits unrestricted non-commercial use distribution, and reproduction in any medium, provided the original work is properly cited. 


\section{Methodology}

The hydrogeologic system and salinity were linked to the groundwater flow model software and map modeling. The geologic and hydrogeologic information and salinity concentrations were collected and compiled to generate spatial distribution and contamination maps. In line with the study purpose and for consistency with current definitions, freshwater was considered to be water comprising a maximum concentration of $1,500 \mu \mathrm{s} /$ $\mathrm{cm}$. The water will no longer be potable once the limit exceeded, therefore additional water treatment is needed or the well must be abandoned or its operation discontinued.

\subsection{Mathematical Simulation Code}

Saltwater intrusion can be mathematically represented by two equations: the flow and the transport equations. Since the density of a liquid depends on the hydraulic conductivity, which in turn depends on the concentration, to correctly simulate salinity diffusion in coastal aquifers, it is necessary to have coupled flow and density-driven transport that makes the saltwater intrusion problem highly nonlinear. These nonlinear equations need to be solved simultaneously to resolve the saltwater intrusion problem.

FEMWATER, a three-dimensional finite element-based, transient, density-driven flow and transport groundwater model of the United States Environmental Protection Agency (EPA), is incorporated to simulate the coastal aquifer under study mathematically. This simulates the flow and transport in both saturated and unsaturated media. Furthermore, the density-dependent problems such as salinity intrusion can be simulated by the coupled flow and transport motion.

The three-dimensional water flow equation is expressed as [8-10]:

$$
\begin{aligned}
& \frac{\rho}{\rho_{o}} F \frac{\partial h}{\partial t}=\nabla\left[K\left(\nabla h+\frac{\rho}{\rho_{o}} \nabla z\right)\right]+\frac{\rho^{*}}{\rho_{o}} q \\
& F=\alpha^{\prime} \frac{\theta}{n}+\beta^{\prime} \theta+n \frac{d S}{d H}
\end{aligned}
$$

where $F$ is the storage coefficient including the effect of unsaturation, water compressibility, and media compressibility; $h$ the hydraulic head; t the time; $K$ the hydraulic conductivity tensor; $z$ the potential head; $q$ the volumetric flow rate of source and/or sink; $\rho_{o}$ the water density at zero salt concentration; $\rho$ the water density at salt concentration; $\rho^{*}$ the density of either the injection fluid or the withdrawn water; $\theta$ the moisture content; $\alpha$ ' the modified compressibility of the medium; $\beta$ ' the modified compressibility of the water; $n$ the porosity of the medium; and $S$ the saturation rate.

The hydraulic conductivity $K$ is a function of density $\rho$ and viscosity $\mu$, as follows [8-10]

$$
K=\frac{\rho g}{\mu} k=\frac{\left(\rho / \rho_{o}\right)}{\left(\mu / \mu_{o}\right)} \frac{\rho_{o} g}{\mu_{o}} k_{s} k_{r}=\frac{\left(\rho / \rho_{o}\right)}{\left(\mu / \mu_{o}\right)} K_{s o} k_{r}
$$

where $\mu$ is the dynamic viscosity of water at chemical concentration; $\mu_{o}$ the dynamic viscosity of water at zero salt concentration; $k$ the permeability tensor; $k_{s}$ the saturated permeability tensor; $k_{r}$ the relative permeability or relative hydraulic conductivity; and $K_{s o}$ the referenced saturated hydraulic conductivity tensor.
The referenced value is usually taken at zero salt concentration. T he density and dynamic viscosity of water are functions of chemical concentration, as shown in Eqs. (4) and (5), respectively [8-10].

$$
\frac{\rho}{\rho_{o}}=a_{1}+a_{2} C+a_{3} C^{2}+a_{4} C^{3}
$$

and

$$
\frac{\mu}{\mu_{o}}=a_{5}+a_{6} C+a_{7} C^{2}+a_{8} C^{3}
$$

where $a_{1}, a_{2}, \ldots, a_{8}$ are the parameters used to define the concentration dependence of water density and viscosity, and $C$ is the chemical concentration.

For saltwater intrusion, the fluid density is taken to be a function of salt concentration as [8-10]:

$$
\rho=\rho_{o}(1+\varepsilon c)
$$

where $c$ is the salt concentration of the seawater (the actual divided by the maximum one), and $\varepsilon$ the dimensionless density reference ratio as defined in Eq. (7) [8-10]:

$$
\varepsilon=\frac{\rho_{\max }}{\rho_{o}}-1
$$

where $\rho_{\max }$ is the maximum density of the seawater, and $\rho_{o}$ the freshwater density.

The Darcy velocity is calculated as follows [8-10]:

$$
V=-K\left(\frac{\rho_{o}}{\rho} \nabla h+\nabla h\right)
$$

The governing equations for transport describe the material transport through the groundwater systems. These equations are obtained on the basis of the law of continuity of mass and flux. The major processes involved in this are advection, dispersion or diffusion, adsorption, decay, biodegradation and injection or withdrawal.

The transport equation is [8-10],

$\theta \frac{\partial c}{\partial t}+\rho_{b} \frac{\partial s}{\partial t}+V \cdot \nabla C-\nabla \cdot(\theta D \cdot \nabla C)=-\left(\alpha^{\prime} \frac{\partial h}{\partial t}+\lambda\right)\left(\theta C+\rho_{b} S\right)-$
$\left(\theta K_{w} C+\rho_{b} K_{s} S\right)+m-\frac{\rho^{*}}{\rho} q C+\left(F \frac{\partial h}{\partial t}+\frac{\rho_{o}}{\rho} V \cdot \nabla\left(\frac{\rho}{\rho_{o}}\right)-\partial \theta / \partial t\right) C$

where $\theta$ is the moisture content; $\rho_{b}$ the bulk density of the medium; $C$ the material concentration in aqueous phase; $S$ the material concentration in adsorbed phase; $t$ the time; $V$ the discharge; $\nabla$ the del operator; $D$ the dispersion coefficient tensor; $\alpha^{\prime}$ the compressibility of the medium; $h$ the pressure head; $\lambda$ the decay constant; $m$ the artificial mass rate; $q$ the source rate of water; $K_{w}$ the firstorder biodegradation rate constant through the dissolved phase; $K_{s}$ the first-order biodegradation rate through the adsorbed phase; and $F$ the storage coefficient.

The flow and transport equations are coupled by the densitycoupling coefficient and by the Darcy velocity terms that render the saltwater intrusion nonlinear.

\subsection{Site Description}

The study area was located along the southern street of 


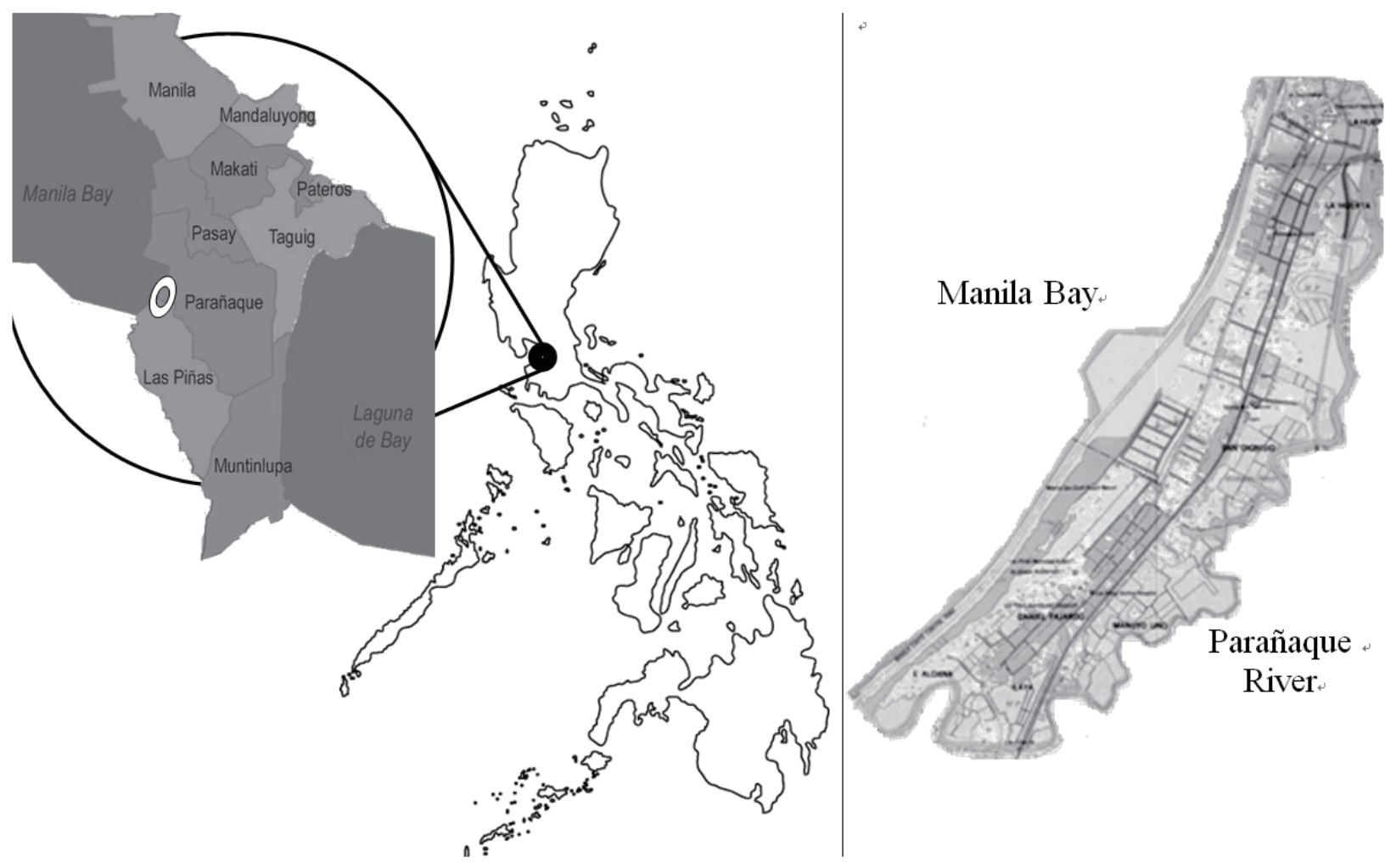

Fig. 1. Location and extent of the study area.

Quirino Avenue of Paranaque and Las Piñas City. It is bounded by Paranaque River on its eastern part and the waters of Manila Bay on its western part as shown in Fig. 1. It is situated on a plain with parts lying along the coastline of scenic Manila Bay, has a relatively flat terrain with an average elevation of $2 \mathrm{~m}$ above mean sea level, and is mainly composed of alluvial soil that is a combination of tuff and sand.

The months between March and May are considered the hot summer period. The temperature dips following intermittent rains and occasional gustiness from June to October. Cool and fair weather prevails from November to February. The area experiences an annual rainfall of $1.82 \mathrm{~mm} / \mathrm{min}$, a temperature range from 23 to $33{ }^{\circ} \mathrm{C}$; a relative humidity of $76 \%$ and an average daylight duration of 12 hours.

In the 2000 Census of the National Statistics Office (NSO), the study area had a total population of 88,583 . The total household population was 88,370 , with 18,548 households [11].

\subsection{Data Collection}

In-situ groundwater testing was conducted from public shallow wells during numerous field visits to the area. The spatial locations (i.e., longitude, latitude) of the surveyed wells were recorded using GPS. The surveyed wells were tested for salinity concentration (electrical conductivity, EC), and water level (hydraulic head). In addition, a wealth of information and data such as maps and drawings, reports, well inventory data, water quality data, and hydrologic data were collected from different agencies including the NWRB, National Mapping and Resource
Information Authority (NAMRIA), Mines and Geosciences Bureau (MGB), and Bureau of Soils.

\subsection{Model Development}

The groundwater system of interest was approximately 2,000 $\mathrm{m}^{2}$, and was covered with a 3D grid. The model grid contained 820 cells with 1,221 nodes. The flow time step $\Delta t$ to recalculate the groundwater flow equation was one hour. The groundwater system consisted of tuff and sand. As such, the hydraulic conductivity $K$ varied from $2.36 \times 10^{-6}$ to $3.00 \times 10^{-3} \mathrm{~m} / \mathrm{sec}$, the porosity $n$ from 0.21 to 0.32 , and the initial EC from 503.6 to $747.5 \mu \mathrm{s} /$ $\mathrm{cm}$.

\section{Results and Discussion}

The collected data were utilized to develop and implement the 3D finite element simulation model. During the in-situ groundwater testing there was no existing evidence of saltwater intrusion in the study area. However, to predict the response of the aquifer system to future withdrawal scenarios, both the flow and transport processes were subsequently modeled using FEMWATER.

FEMWATER models the density-dependent coupled flow and transport processes in the aquifer. The simulation model was not calibrated due to insufficient available data for satisfactory calibration and validation of the model. The given parameter values and boundary conditions were utilized as representative 


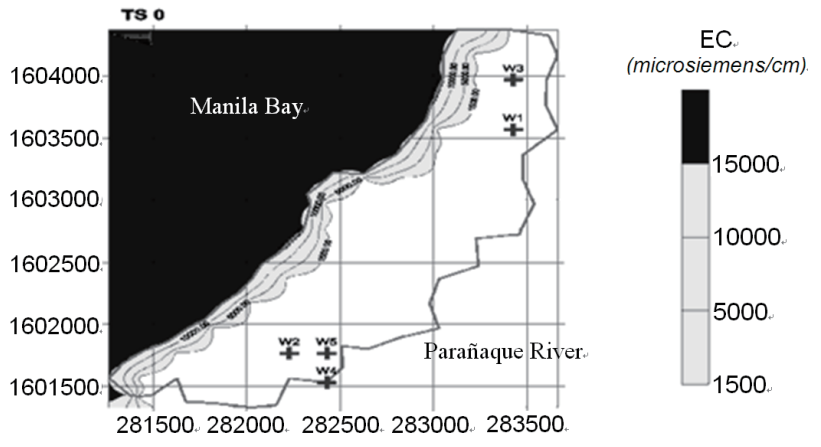

Fig. 2. Present salinity concentration of the aquifer.

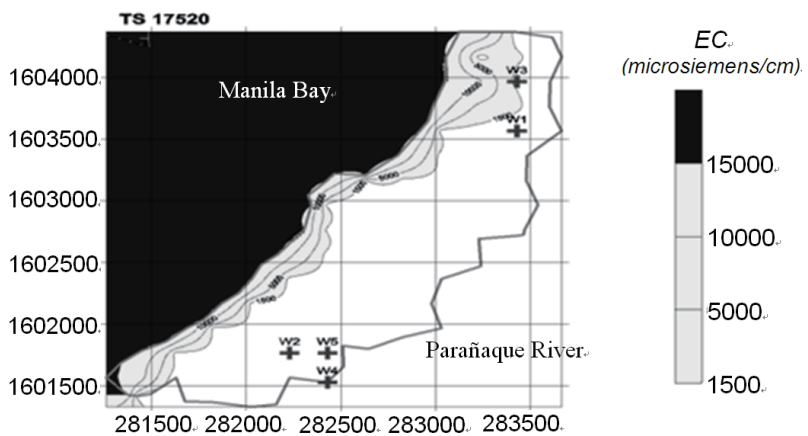

a Salinity concentration of the aquifer after two (2) years.

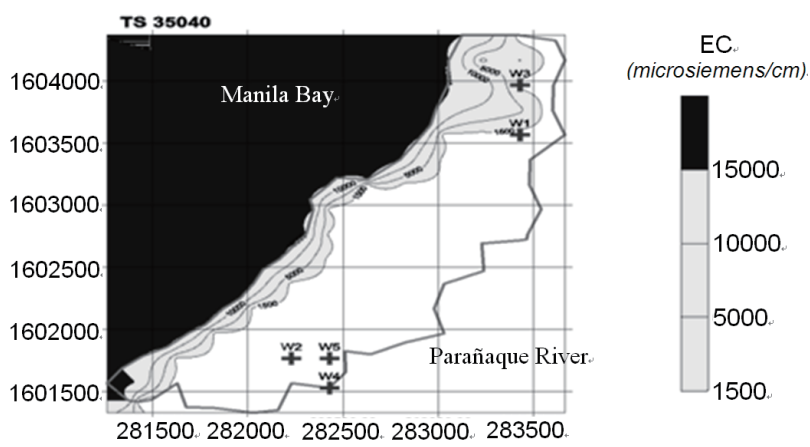

(b) Salinity concentration of the aquifer after four (4) years.

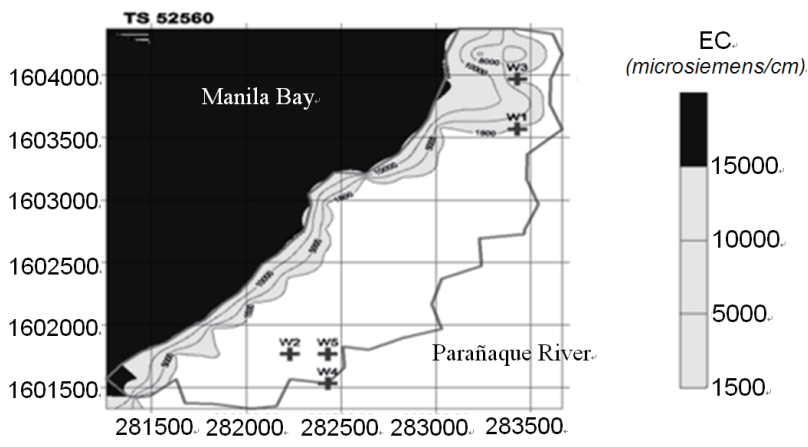

C Salinity concentration of the aquifer after six (6) years.

Fig. 3. Forecasted salinity concentration scenarios. information for the study area. In addition, the basic study objective was to predict the extent and degree of the salinity concentration in the study area.

To meet these study objectives, the simulation model was used to simulate the aquifer conditions for the present discharge scenarios, and five other scenarios to forecast the possible condition of the aquifer in ten years.

Fig. 2 shows the present salinity concentration of the aquifer based from the actual testing of the groundwater quality of wells, the present salinity concentration of the groundwater ranged from $500-700 \mu \mathrm{s} / \mathrm{cm}$, and could thereby be classified as fresh and potable water.

Fig. 3 shows the different simulation model scenarios. Areas with

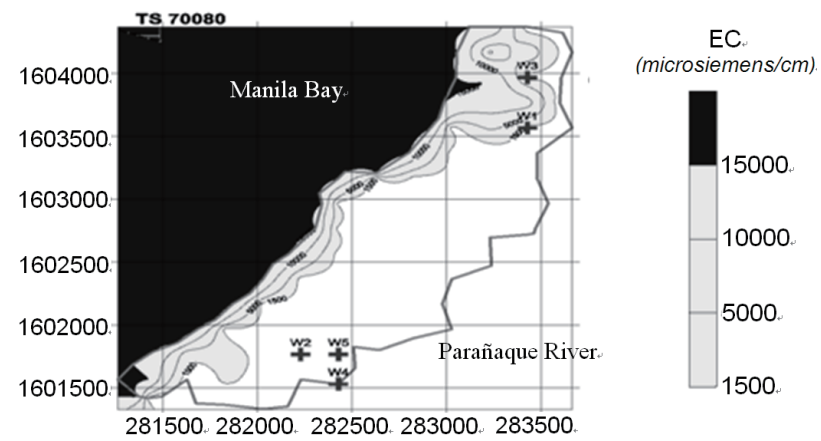

d Salinity concentration of the aquifer after eight (8) years.

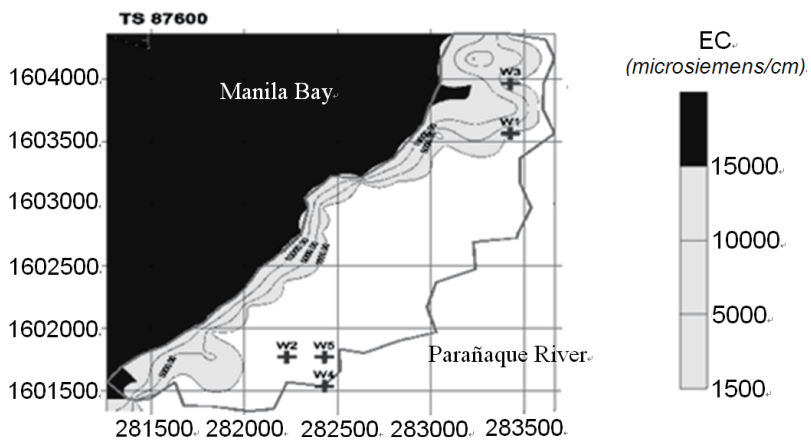

e Salinity concentration of the aquifer after ten (10) years.

EC greater than $1,500 \mu \mathrm{s} / \mathrm{cm}$, shown as the shaded portion in the study area, were considered areas encroached by landward movement of seawater. The result indicated that areas closer to the sea will be the first affected by the landward movement of seawater flowing into areas of reduced aquifer pressures due to excessive groundwater extraction. More specifically, areas that extract a large volume of groundwater will be severely affected by the saltwater intrusion.

\section{Application}

The primary output of this study is the groundwater and salinity contamination model of the coastal aquifer of the study area, which generates simulation results of the present and 
projected conditions. This pioneering simulation of the aquifer will provide a reference for other researchers. Future researchers studying groundwater management and remediation procedures will have baseline data and a working model capable of visualizing the extent of the aquifer contamination. From this, they will be able to form initial predictions regarding the cause of the problem and how to control and resolve this serious issue.

\section{Conclusions and Recommendations}

A saltwater intrusion model for the aquifer was generated using 3D finite element method. After determining the salinity concentration of the aquifer, the concentration contour was plotted. The model showed that after 10 years, the aquifer will be subjected to severe saltwater intrusion from the Manila Bay, and that upper portion of the study area will be the most likely affected areas due to their higher discharge rates than the other areas.

The salinity may possibly come to cover the whole aquifer, with the continual slow penetration of saltwater into other portions of the aquifer. It is therefore concluded that this model can be used as a basis to provide reliable data for projecting saltwater contamination for the management and development of groundwater resources.

In future studies on saltwater intrusion modeling, we recommend the following four issues be focused on:

1) To conduct occasional actual testing of the salinity concentration of the groundwater, sea and the river in order to revalidate the simulated data.

2) To gather for further study and research any distinctive data that different agencies lack.

3) To validate the actual discharge of the wells and re-run the model if possible.

4) To develop guidelines for the cautious management and urgent development of groundwater studies due to the great risk of saltwater contamination in the aquifer.

\section{References}

1. The World Bank. Philippines Environment Monitor 2003: Water Quality. Available from: http://www.worldbank.org. $\mathrm{ph} /$ WBSITE/EXTERNAL/COUNTRIES/EASTASIAPACIFICEXT/PHILIPPINESEXTN/0,,contentMDK:20209686 pa gePK:141137 piPK:217854 theSitePK:332982 isCURL:Y,00. html.

2. Thorpe, GS. Barron's AP environmental science. New York: Barron's Educational Series, Inc. 2009.

3. Bear, J, Cheng, AHD, Sorek, S, Ouazar, D and Herrera, I (eds.). Seawater intrusion in coastal aquifers - concepts, methods and practices. Dordrecht, The Netherlands: Kluwer Academic Publisher; 1999.

4. Bear, J. Hydraulics of groundwater. New York: McGraw-Hill; 1979.

5. Sherif MM, Singh VP. Saltwater Intrusion. In: Singh VP, ed. Hydrology of disasters. Dordrecht ; Boston: Kluwer Academic Publishers; 1996. p. 269-316.

6. National Water Resources Board (NWRB). Water resources assessment for prioritized critical areas (phase 1). 2004.

7. Kumar, C. P., "Management of Groundwater in Salt Water Ingress Coastal Aquifers”, In: Ghosh, N. C., Sharma, K.D. (Eds), Groundwater modelling and management. New Delhi: Capital Publishing company; 2006, p. 540-560.

8. Lin HJ, Richards DR, Talbot CA, et al. FEMWATER: a threedimensional finite element computer model for simulating density-dependent flow and transport in variably saturated media. Coastal and Hydraulics Laboratory; 1997. Report No.: Technical Report CHL-97-12. Available from: http://homepage.usask.ca/ mjr347/gwres/femwref.pdf.

9. Tularam GA, Singh R. Estuary, river and surrounding groundwater quality deterioration associated with tidal intrusion. $J$. Appl. Sci. Environ. Sanit. 2009;4:141-150.

10. 3DFEMWATER/3DLEWASTE: numerical codes for delineating wellhead protection areas in agricultural regions based on the assimilative capacity criterion. Washington, DC: US Environmental Protection Agency; 1992.

11. National Statistics Office. c2000. Census of population and housing-national report. Available from: http://www.census.gov.ph/census2000/index.html. 